\title{
Notas sobre o estabelecimento da concordância de número em construções partitivas no português brasileiro e no português europeu ${ }^{1}$
}

\author{
Mirian Santos Cerqueira ${ }^{2}$
}

\section{Resumo}

Este artigo pretende apresentar os resultados de uma pesquisa sobre o estabelecimento da concordância sujeitoverbo em construcões partitivas em português brasileiro e português europeu. Para isso, está organizado em três seções. Na primeira, apresentamos uma breve discussão acerca de um estudo sobre o processamento da concordância de número em sentenças com construções partitivas em português brasileiro (RODRIGUES, 2006). Na segunda seção, descrevemos e analisamos os resultados de um teste de julgamento de gramaticalidade a partir do qual investigamos o estabelecimento da concordância em construções partitivas em português brasileiro e português europeu (CERQUEIRA, 2009). $\mathrm{Na}$ última seção, concluímos que a concordância em questão pode ser explicada considerando-se a Operação Agree, interpretada como compartilhamento de traços, conforme proposta assumida por Frampton \& Gutmann (2000).

Palavras-chave: Concordância sujeito-verbo. Construções partitivas. Português brasileiro. Português europen

\footnotetext{
${ }^{1}$ Esta pesquisa recebeu o apoio financeiro de uma bolsa do CNPq e de uma bolsa da Capes, em períodos distintos de sua realização.

${ }^{2}$ Professora adjunta na Universidade Federal de Goiás.
} 


\section{Introdução}

No âmbito da Sintaxe Experimental, muitos são os trabalhos desenvolvidos sobre o tema do processamento da concordância verbal cujos principais objetivos estão atrelados a uma busca pela compreensão do funcionamento da formulação de sentenças. Considerando tal fato, o presente artigo tem como objetivos principais: (i) uma descrição do estudo de Rodrigues (2006) acerca do processamento da concordância de número entre sujeito e verbo na produção de sentenças, a fim de fornecer uma explicação para os erros de atração $^{3}$ de concordância e para a variabilidade de concordância nas construções partitivas; (ii) uma apresentação dos resultados de um teste de preferência a que foram submetidos falantes do Português Brasileiro (PB) e do Português Europeu (PE) (CERQUEIRA, 2009) com vistas a analisar a concordância sujeito-verbo em construções partitivas introduzidas pelos itens maioria e parte; (iii) a elaboração de uma proposta de análise para o estudo da concordância de número nas construções partitivas.

Embora os chamados erros de atração não sejam exatamente o foco do presente artigo e nossa pesquisa não seja voltada para a Sintaxe Experimental, torna-se relevante abordá-los, uma vez que podem trazer algum tipo de evidência empírica para melhor compreensão da concordância sujeito-verbo nas construções investigadas. O estudo dessas, por sua vez, poderá lançar luz à compreensão daqueles. Para tanto, este artigo está organizado da seguinte maneira: na primeira seção, aborda o trabalho de Rodrigues (2006) sobre o processamento de número na concordância sujeito-verbo no Português Brasileiro, tanto em construções formadas por $\mathrm{DPs}^{4}$ complexos, quanto em construções partitivas, em que essa autora utiliza pressupostos teóricos advindos do Programa Minimalista e de uma teoria de formulação da sentença. $\mathrm{Na}$ segunda, apresenta os resultados do estudo desenvolvido por Cerqueira (2009) acerca das construções partitivas em PB e PE. Na terceira seção, faz a explanação de uma proposta de análise para as construções em questão, tomando a operação Agree e seus desdobramentos mais recentes como ponto de partida (FRAMPTON \& GUTMANN, 2000).

\footnotetext{
${ }^{3}$ Erro de atração, segundo Rodrigues (2006, p. 15), "se caracteriza pela concordância do verbo com um núcleo nominal interveniente entre aquele e o núcleo do sujeito".

${ }^{4}$ As siglas utilizadas no presente artigo são as seguintes: DP (do inglês Determiner Phrase = Sintagma de Determinante); EPP (do inglês Extended Projection Principle = Princípio de Projeção Estendido); PB (Português Brasileiro); PE (Português Europeu); PP (do inglês Prepositional Phrase = Sintagma Preposicional); VP (do inglês Verbal Phrase = Sintagma Verbal); $\nu \mathrm{P}$ (do inglês Light Verbal Phrase = Sintagma de Verbo Leve); $v$ (do inglês Light Verb = Verbo Leve); NP (do inglês Noun Phrase = Sintagma Nominal); Traços- $\square \square$ (Traços-phi = Traços de Concordância); e TP (do inglês Tense Phrase = Sintagma de Tempo); T (do inglês Tense $=$ Tempo).
} 


\section{Expressões partitivas e DPs complexos: o processamento da concordância de número no português brasileiro}

Rodrigues (2006) analisa o processamento de número da concordância entre sujeito e verbo na produção de sentenças declarativas finitas em $\mathrm{PB}$, procurando articular um modelo teórico ${ }^{5}$ de processamento de sentença fundamentado na Sintaxe Experimental à teoria linguística, representada, neste caso, pelo Programa Minimalista. Inicialmente, a autora propõe-se a estabelecer uma distinção entre as construções partitivas, cuja concordância morfologicamente visível se realiza de duas formas, ambas licenciadas pela gramática da língua e julgadas gramaticais pelos falantes (conforme apresentado em (2), e as construções com DPs complexos, julgadas agramaticais pelos falantes (conforme apresentado em (1).

(1) A análise dos resultados experimentais indicaram um efeito principal de número do núcleo interveniente no processamento da concordância.

(2) A maioria dos erros ocorreu/ocorreram após preâmbulos em que havia incongruência de número entre o núcleo do sujeito e o núcleo interveniente.

Nos dois tipos de construção, tem-se uma marcação de número plural no núcleo nominal contido no DP mais encaixado, o qual funciona como modificador do sujeito. Partindo do fato de que os dois tipos de construção são distintos, a autora irá propor que devam ser analisados de forma diferenciada, levando em conta tanto o processamento da sentença pelos falantes, quanto a explicação do ponto de vista da teoria linguística para a derivação sintática.

A autora justifica sua escolha teórica argumentando que a noção de derivação de uma sentença, na teoria linguística, é compatível com o modelo de produção/formulação de sentença adotado, uma vez que leva em conta a aplicação de sucessivas operações computacionais (RODRIGUES, 2006, p. 32).

Como consequência dessa escolha, a autora irá assumir a ideia segundo a qual a gramática tem sua autonomia em relação ao processador ${ }^{6}$, o que a leva a adotar um modelo

\footnotetext{
${ }^{5}$ A esse respeito, o trabalho de Augusto (2005) parece ser bastante elucidativo, uma vez que discute questões relacionadas ao diálogo estabelecido entre Teoria Linguística e Psicolinguística.

6 Acerca da discussão entre teorias de competência e teorias de performance, Chomsky (1995, p. 57) argumenta que "uma hipótese empírica aceite é que uma das componentes da mente/cérebro é um processador,
} 
de processamento separado da gramática, qual seja o modelo baseado na proposta de Corrêa (2005; 2006). Esse modelo recebe a designação de modelo PMP (Produção Monitorada por Parser).

Rodrigues (2006) argumenta que tal modelo é compatível com a visão de modularidade da teoria linguística adotada para o estudo da gramática. Como consequência, defende que os erros de atração encontrados nos testes experimentais produzidos pelos falantes não "afetam" a computação sintática, uma vez que seriam decorrentes de operações pré ou pós-sintáticas, e não de operações do sistema computacional propriamente dito.

Do ponto de vista metodológico, inicialmente, Rodrigues propõe uma tarefa Psicolinguística a um grupo de falantes do dialeto padrão brasileiro. Ao todo são realizados 5 experimentos psicolinguísticos a fim de verificar, por meio de julgamento de gramaticalidade da sentença, possíveis diferenças no processamento da concordância entre os DPs complexos e as construções partitivas. Os testes compreendem diferentes variáveis, levando em conta fatores sintáticos, morfofonológicos e semânticos.

O primeiro experimento teve como objetivo principal analisar a interação entre as variáveis independentes: distância linear entre o núcleo do sujeito e o verbo (curta ou longa) e o tipo de modificador (PP e oração relativa). Para tanto, procedeu-se à manipulação da primeira variável (distância linear) introduzindo-se um PP modificador do núcleo nominal interveniente (p. 145), conforme condições exemplificadas em C1-C4:

C1: distância linear curta e modificador $P P$

O diretor arrogante dos funcionários.

C2: distância linear curta e modificador Oração Relativa

O jornalista que falou dos empresários

C3: distância linear longa e modificador PP

O instrutor calmo dos pilotos de avião

que atribui uma representação perceptual a um sinal (abstraindo de outras circunstâncias para a interpretação. Presumivelmente, o processador incorpora a língua e muitas coisas mais: a hipótese é que a interpretação implica um tal sistema, encaixado noutros" (grifo do autor). 


\section{C4: distância linear longa e modificador Oração Relativa}

\section{$O$ ator que discordou dos críticos de teatro}

Como resultado, Rodrigues (2006) verifica que a variável distância linear apresentou um efeito significativo, diferentemente da variável tipo de modificador e da interação entre ambas as variáveis. Esse resultado, segundo a autora, é compatível com a ideia segundo a qual a manutenção da representação do DP sujeito gerada pelo parser seria afetada pela distância entre o núcleo do sujeito e verbo, dificultando por conseguinte a recuperação da informação de número do núcleo do sujeito.

Concernente ao segundo experimento, procurou-se verificar a previsibilidade de erros de atração com relação ao contraste entre posição linear e posição bierárquica do núcleo nominal interveniente. Adicionalmente, foi observado o valor do traço de número do núcleo do sujeito, a fim de verificar se a concordância seria afetada por ele. Os resultados obtidos apontam a posição hierárquica do núcleo interveniente como sendo a propriedade responsável pela previsão de erros de atração no processamento da concordância entre o sujeito e o verbo, levando em conta as seguintes condições favorecedoras: (i) distância linear longa entre o núcleo do sujeito e o verbo; (ii) núcleo do sujeito no singular; e (iii) núcleo interveniente mais alto no plural.

Com relação ao efeito de marcação, o fator desencadeador dos erros de atração é a visibilidade da informação de número no DP sujeito. A autora faz referência ao fato de os resultados obtidos aproximarem-se dos resultados obtidos em Franck, Vigliocco \& Nicol (2002) para o inglês. Todavia, a autora chama a atenção para o fato de no inglês o elemento que ancora a informação de número ser obrigatoriamente o nome; contrariamente ao português brasileiro (em alguns dialetos), que marca explicitamente tanto no nome quanto no determinante, valendo ressaltar que, conforme atestam Scherre \& Naro (1998), quando se trata dos DPs, essa informação de número recai sempre no determinante.

Segundo Rodrigues, esses resultados se distanciam daqueles obtidos por Franck, Vigliocco e Nicol (2002) no que se refere aos dados do francês. Tal resultado, segundo a autora, pode ser atribuído ao fato de não haver, em francês, uma distinção tão explícita entre o singular e plural, a despeito do que é observado no português e no inglês. 
Com relação ao terceiro experimento, objetivou-se verificar em que medida o status argumental do PP (se argumento, se adjunto) que contém o núcleo interveniente no DP sujeito seria decisivo no processamento da concordância. A autora argumenta, com base em Matthews \& Chodorow (1988), que a incidência de um maior número de erros após PPs argumentos estaria associada à posição estrutural de cada um dos constituintes, uma vez que essa posição poderá determinar o grau de acessibilidade de representações na memória. Em se tratando de PPs argumentos, estes seriam mais determinantes no processamento da concordância "por estarem mais fortemente vinculados à estrutura sintática” (RODRIGUES, 2006, p. 159).

O quarto experimento teve como principais objetivos verificar a relação entre distributividade e marcação morfofonológica. Com efeito, buscou-se observar se haveria efeito de distributividade na concordância entre o sujeito e o verbo, como também verificar, através do emprego do operador "cada", se haveria interferência na concordância com sintagmas em que a leitura distributiva não estivesse necessariamente associada à marca de pluralidade de um núcleo interveniente.

Além disso procurou-se verificar se o "s" final do número interveniente deflagraria erros de atração e se na computação sintática seriam consideradas diferenças com relação à codificação morfofonológica de número no núcleo interveniente em DPs locais (p. 160).

Para isso, foi utilizado o operador "cada" em DPs do tipo: C1: O trinco de cada porta; C2: A roda de cada ônibus; C3: A maçaneta das portas; C4: O volante dos ônibus.

O resultado obtido por esse experimento mostra que houve um maior número de erros nas condições em que o DP do nome local era plural, ou seja, não compatível com o número do núcleo do sujeito (RODRIGUES, 2006, p. 162).

Além dos resultados ora apresentados acerca dos experimentos realizados por Rodrigues, interessa verificar, ainda, a discussão trazida pela autora acerca das propriedades dos itens maioria e parte, e analisar de que maneira a proposta formulada pela autora pode dar conta ou não dos casos estudados.

Rodrigues (2006) assume que os elementos de natureza partitiva maioria e parte podem manifestar propriedades categoriais de natureza lexical e/ou funcional. Quando lexicais, esses nomes ocupariam a posição de núcleo de um NP, sendo responsável pelo 
controle da concordância com a flexão verbal. Diferentemente, quando funcionais, os itens maioria e parte ocupariam a posição de quantificadores de nome, sendo o DP contido no PP o sujeito de uma Small Clause e os itens maioria e parte os predicados dessa Small Clause. Essa ideia, postulada por Rodrigues para as partitivas em português, fundamenta-se em Covert \& Zwarts (2004).

A autora salienta, ainda, que a presença de um adjetivo modificando os itens parte e maioria também teria influência no desencadeamento da concordância, uma vez que restringiriam a forma verbal ao singular, conforme os exemplos apontados em:

(3) A grande maioria dos alunos reclamou/?*reclamaram da prova de matemática.

(4) A maioria inteligente dos alunos conseguiu/?* conseguiram fazer o trabalho.

Rodrigues (2006) argumenta que, quando posposto, o adjetivo atuaria de forma mais decisiva para levar o verbo ao singular; contrariamente, quando anteposto, dificultaria a precisão do julgamento da sentença.

A autora argumenta, ainda, que uma outra possibilidade de análise para a concordância plural com o DP definido em construções partitivas seria assumir uma explicação tomando como base uma estrutura de adjunção de DP a DP, conforme propõe Avelar (2005a; 2005b) ao analisar o comportamento de constituintes encabeçados por sintagma-de, contrastando com o comportamento daqueles encabeçados por sintagma-com.

Rodrigues, então, descreve de que maneira ocorreria a valoração do traço nãointerpretável de número do núcleo funcional T com o traço de número do DP partitivo. No entanto, ela questiona a arbitrariedade da escolha do DP, pois uma vez que ocorre adjunção de DP a DP, o núcleo funcional T poderia enxergar tanto o DP [a maioria] quanto o DP partitivo complemento de [maioria].

Adicionalmente, Rodrigues ressalta que a ideia de concordância facultativa proposta pela Gramática Normativa é totalmente inadequada à concordância nas partitivas, uma vez que, segundo a autora, essa dupla possibilidade seria desencadeada pelo fato de serem decorrentes de numerações distintas, do que resultaria que em cada uma dessas numerações os itens maioria e parte portariam um conjunto diferenciado de traços (RODRIGUES, 2006, p. 100). 


\section{As construções partitivas introduzidas pelos itens maioria e parte: notas sobre juízos de gramaticalidade}

Com o propósito de tentar compreender de que maneira a concordância sujeitoverbo se manifesta nas gramáticas do PB e do PE em se tratando das construções partitivas introduzidas pelos itens maioria e parte, mais especificamente, à semelhança ${ }^{7}$ do que fez Rodrigues (2006) em relação ao PB, apresentamos, nesta seção, os resultados de um teste de preferência ${ }^{8}$ realizado com falantes do PB e do PE, alunos de Fonoaudiologia e de Terapia da Fala, respectivamente, compreendendo a faixa etária de 17 a 28 anos. Tais testes foram realizados com o intuito de analisar semelhanças e/ou diferenças com relação aos julgamentos de gramaticalidade desses falantes.

\section{Descrição e análise do teste aplicado a falantes brasileiros e portugueses}

Este teste teve como principal objetivo analisar em que medida os falantes das línguas investigadas apresentam variação de julgamento quanto à escolha das formas de concordância nas partitivas e se isso está, de alguma forma, relacionado ao tipo de nome partitivo maioria e parte, ao tipo de verbo, à natureza do DP subcategorizado pelo PP complemento do item partitivo, aos traços dos nomes contidos no DP mais encaixado, dentre outros fatores. Para tanto, procedeu-se da seguinte maneira: tanto em relação ao PB quanto em relação ao PE, solicitou-se aos informantes que preenchessem as lacunas das frases propostas, de forma a flexionar o verbo em gênero (masculino ou feminino) e em número (singular ou plural), em conformidade com o que acreditam dizer normalmente. Ao todo foram testadas 10 frases, sem qualquer frase distratora, conforme se verifica no exemplo abaixo:

(1) A maioria dos lápis de cor (Estar com defeito).

As frases foram distribuídas de forma a contemplar 05 pares de frases, contendo, cada uma delas, as seguintes expressões: (i) A maioria de; (ii) Uma parte de; (iii) A maior parte

\footnotetext{
${ }^{7}$ A semelhança aqui se refere apenas à escolha dos itens partitivos parte e maioria com o objetivo de saber qual deles favorece mais a concordância em questão. O nosso estudo se distancia radicalmente da pesquisa de Rodrigues (2006) uma vez que esta realiza experimentos psicolinguísticos com os falantes do PB.

8 Em uma tese de doutorado, desenvolvemos três testes de julgamento de gramaticalidade a falantes brasileiros e portugueses. No entanto, para este artigo, por questão de espaço, apresentamos apenas os resultados de um deles, ou seja, do segundo teste, que aqui é denominado apenas de teste de preferência.
} 
Notas sobre o estabelecimento da concordância de número em construções partitivas no Português Brasileiro e no Português Europeu

Mirian Santos Cerqueira

de; (iv) Grande parte de; e (v) Uma minoria de. Cada uma dessas expressões foram testadas levando-se em conta as seguintes variáveis:

1. Tipo de nome contido no núcleo nominal do DP complemento: pluralia tantum, nome flexionável

2. Tipo de verbo: inacusativo, acusativo

3. Traço de gênero presente no adjetivo modificador: feminino ou masculino

4. Traço de número presente no adjetivo: singular ou plural

(2) A maioria dos óculos de grau/graduados (ser caro).

\begin{tabular}{|c|c|c|c|c|c|}
\hline \multicolumn{2}{|c|}{ PB } & \multicolumn{3}{c|}{ PE } \\
\hline \multicolumn{2}{|c|}{ Singular } & Plural & \multicolumn{2}{c|}{ Singular } & Plural \\
\hline Masc. & Fem. & Masc. & Masc. & Fem. & Masc. \\
\hline 02 & 02 & 13 & 01 & & 16 \\
\hline
\end{tabular}

Percebe-se nesse contexto, uma variação mais acentuada em relação às respostas dadas pelos falantes do PB, sendo a forma masculino plural a que mais aparece, assim como em PE.

a) Tipo de expressão partitiva: uma parte de

Tipo de nome contido no núcleo nominal do DP complemento: substantivo_masculino plural

Tipo frase: ativa

Tipo de verbo: transitivo

(3) Uma parte dos professores (comprar) os livros.

\begin{tabular}{|c|c|c|c|}
\hline \multicolumn{2}{|c|}{ PB } & \multicolumn{2}{c|}{ PE } \\
\hline Singular & Plural & Singular & Plural \\
\hline 07 & 10 & 08 & 09 \\
\hline
\end{tabular}


Notas sobre o estabelecimento da concordância de número em construções partitivas no Português Brasileiro e no

b) Tipo de expressão partitiva: uma parte de seguida de DP complemento contendo núcleo nominal formado por nome masculino plural

Tipo de frase: passiva

(4) Uma parte dos livros (ser vendido).

\begin{tabular}{|c|c|c|c|}
\hline \multicolumn{2}{|c|}{ PB } & \multicolumn{2}{c|}{ PE } \\
\hline Singular & Plural & Singular & Plural \\
\hline 06 & 11 & 04 & 13 \\
\hline
\end{tabular}

É interessante notar que em PB o traço de número no verbo estabelece uma relação com o traço de gênero, verificando-se em alguns contextos uma hierarquia desses traços, resultando na manifestação dos seguintes padrões:

(i) traço de gênero masculino+traço de número: singular (ex.: foi vendido)

(ii) traço de gênero feminino+traço de número: singular (ex.: foi vendida)

(iii) traço de gênero masculino+traço de número: plural (ex.: foram vendidos)

c) Tipo de Expressão: a maior parte de seguida de DP complemento contendo núcleo nominal formado por nome feminino plural (PB) e nome masculino plural (PE).

Tipo de verbo: inacusativo

(5) Uma parte das crianças/dos miúdos (chegar).

\begin{tabular}{|c|c|c|c|}
\hline \multicolumn{2}{|c|}{ PB } & \multicolumn{2}{c|}{ PE } \\
\hline Singular & Plural & Singular & Plural \\
\hline 05 & 12 & 06 & 11 \\
\hline
\end{tabular}

d) Tipo de Expressão: a maior parte de

Traço de gênero do núcleo nominal contido no DP complemento: masculino

Revista Leitura v. 2, nº 59 - Maceió - Jul./Dez. 2017 - ISSN 2317-9945

Homenagem a Denilda Moura, p. 64-84 
Tipo de verbo: inacusativo

(6) A maior parte dos pneus (furar).

\begin{tabular}{|c|c|c|c|}
\hline \multicolumn{2}{|c|}{ PB } & \multicolumn{2}{c|}{ PE } \\
\hline Singular & Plural & Singular & Plural \\
\hline 07 & 10 & 07 & 10 \\
\hline
\end{tabular}

É importante ressaltar que não foram feitas distinções entre morfemas modotemporal, uma vez que o que estava sendo testado era o valor do traço de número. Assim, foram consideradas todas as variações possíveis: furam/fura; furou/furaram, estão furados e, no caso do PE, a ocorrência do clítico como em furou-se/furaram-se.

e) Tipo de Expressão: grande parte de seguida de DP complemento contendo núcleo nominal formado por nome feminino plural

Tipo de verbo: recíproco

(7) Grande parte das pessoas (alimentar-se) mal.

\begin{tabular}{|c|c|c|c|}
\hline \multicolumn{2}{|c|}{ PB } & \multicolumn{2}{c|}{ PE } \\
\hline Singular & Plural & Singular & Plural \\
\hline 06 & 11 & 07 & 10 \\
\hline
\end{tabular}

Em se tratando do $\mathrm{PB}$, pôde-se verificar uma variação quanto à posição do clítico se, aparecendo na maior parte dos casos como proclítico ao verbo.

f) Tipo de Expressão: grande parte de seguida de DP complemento contendo núcleo nominal formado por nome masculino

Tipo de verbo: acusativo

(8) Grande parte dos estudantes (Fazer) o trabalho. 


\begin{tabular}{|c|c|c|c|}
\hline \multicolumn{2}{|c|}{ PB } & \multicolumn{2}{c|}{ PE } \\
\hline Singular & Plural & Singular & Plural \\
\hline 06 & 11 & 04 & 13 \\
\hline
\end{tabular}

g) Tipo de Expressão: uma minoria de

Traço de gênero do nome contido no núcleo nominal do DP complemento: masculino

Tipo de verbo: inacusativo

Tipo de frase: passiva

(9) Uma minoria dos resumos (ser aceite) para o congresso.

\begin{tabular}{|c|c|c|c|c|c|}
\hline \multicolumn{3}{|c|}{ PB $^{9}$} & \multicolumn{2}{c|}{ PE } \\
\hline \multicolumn{2}{|c|}{ Singular } & \multicolumn{2}{c|}{ Plural } & Singular & Plural \\
\hline Masc. & Fem. & Masc. & Fem. & 7 & 10 \\
\hline $\mathbf{3}$ & $\mathbf{2}$ & $\mathbf{9}$ & $\mathbf{0}$ & & \\
\hline
\end{tabular}

h) Tipo de Expressão: uma minoria de

Traço de gênero do nome contido no núcleo nominal do DP complemento: masculino

Traço de número: plural

Tipo de modificador: adjetivo masculino plural

Tipo de verbo: inacusativo

Tipo de frase: passiva

\footnotetext{
${ }^{9}$ Vale observar que três falantes do PB forneceram resposta incompleta. Em relação ao PE, é preciso destacar que a forma participial aceite é invariável para gênero.
} 
(10) Uma minoria dos fumantes/fumadores portugueses (protestar) ontem contra a nova lei.

\begin{tabular}{|c|c|c|c|}
\hline \multicolumn{2}{|c|}{ PB } & \multicolumn{2}{c|}{ PE } \\
\hline Singular & Plural & Singular & Plural \\
\hline $\mathbf{5}$ & 12 & 10 & $\mathbf{7}$ \\
\hline
\end{tabular}

\section{Síntese e discussão dos resultados}

Com base nos dados apresentados pelo teste aplicado aos falantes do PB e do PE (CERQUEIRA, 2009), bem como a partir da verificação da variação da concordância em construções partitivas atestada por Rodrigues (2006), a ideia central consistiu em demonstrar de que maneira a realização da concordância morfologicamente visível entre o DP sujeito e o núcleo flexional é estabelecida nas construções partitivas em português brasileiro e português europeu, permitindo visualizar melhor as diferenças entre os julgamentos dos falantes do PB e do PE. Isso nos levou a formular a proposta que será descrita na seção seguinte.

\section{Operação Agree e construções partitivas: uma proposta de análise para a concordância sujeito-verbo}

A perpectiva gerativista para o estudo da concordância advoga a favor da ideia segundo a qual a concordância ocorre devido a um processo de valoração que se aplica a duas instâncias distintas de um dado traço. $O$ elemento que possui traços não interpretáveis, denominado Probe (sonda), entra em combinação com um elemento que possui traços interpretáveis, denominado Goal (alvo), o qual valora os traços da sonda por meio de uma combinação (matching), devendo a Sonda c-comandar o Alvo, o qual deve estar em seu domínio local, não devendo haver qualquer elemento interveniente entre ambos (CHOMSKY, 1995 e obras seguintes).

A partir disso, passamos a apresentar as seguintes questões: 
Notas sobre o estabelecimento da concordância de número em construçôes partitivas no Português Brasileiro e no Português Europeu

Mirian Santos Cerqueira

1. O que é "enxergado" pela sonda T no momento em que esta busca um alvo para valorar seus traços-phi? Os traços do nome partitivo [maioria] ou os traços do núcleo nominal [professores]?

2. Pode-se pensar em "opcionalidade", uma vez que a concordância pode ser estabelecida entre a sonda $\mathrm{T}$ e qualquer um dos núcleos nominais contidos no DP sujeito?

3. Que traços os núcleos nominais contidos no DP sujeito de uma construção partitiva devem possuir para que possam ser escolhidos para entrar em relação de concordância com a sonda T?

Antes de tentarmos responder as questões apresentadas, vejamos o processo de derivação de uma sentença em que a concordância se estabelece com o segundo núcleo nominal do DP sujeito [os professores]. Para melhor ilustrar a operacionalização do mecanismo de concordância nas partitivas, adotamos a derivação de uma sentença e apagamento de traços não interpretáveis, com base em Avelar (2006) ${ }^{10}$, fazendo as adaptações necessárias para o fenômeno investigado no presente artigo. Veja-se a numeração e a consequente derivação de uma sentença com o verbo na forma plural:

A maioria dos professores compraram os livros.

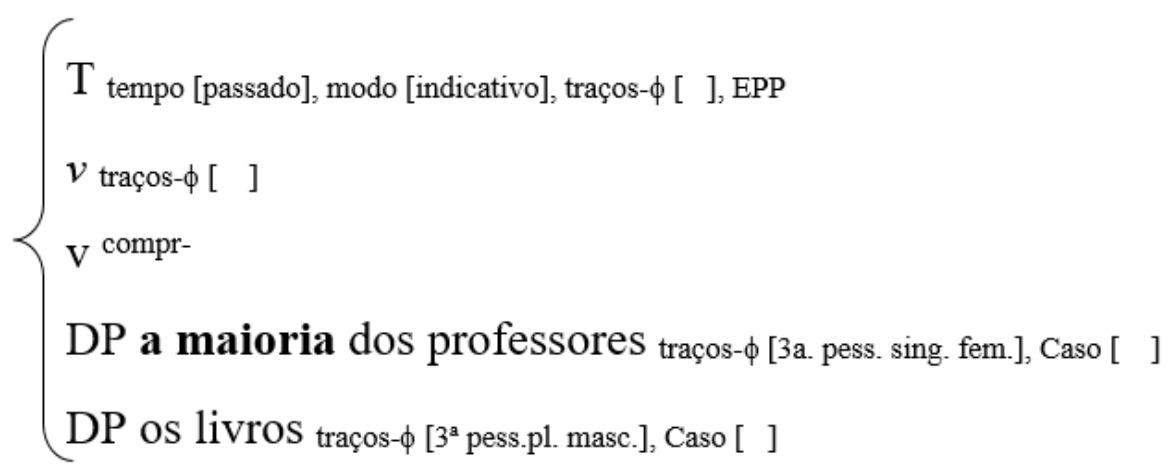

\footnotetext{
${ }^{10}$ Para melhor ilustrar os passos derivacionais e as operações de sondagem, valoração (aqui substituída por compartilhamento, uma vez que adoto a proposta de Frampton \& Gutmann, 2000a) e apagamento (aqui entendido como inércia) de traços não-interpretáveis, segui o modelo apresentado em Avelar (2006). Vale ressaltar, ainda, como bem mostrou o autor, que na proposta minimalista de Bare Phrase Structure projeções máximas e mínimas devem ser compreendidas como propriedades relacionais apenas, não inerentes a qualquer categoria. Segundo Avelar (2006, p. 57), "qualquer artifício simbólico como nós, barras, subíndices e outros elementos que venhamos a inserir na estrutura não passa, agora, de mera informação notacional com objetivos expositivos, sem qualquer referência a propriedades inerentes à estrutura".
} 
$1^{\circ}$ passo: conexão de compr-ao DP os livros

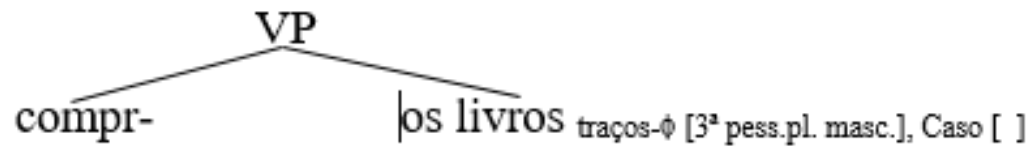

$2^{\circ}$ passo: compartilhamento de traços- $\square$ de v e do traço de Caso do nome

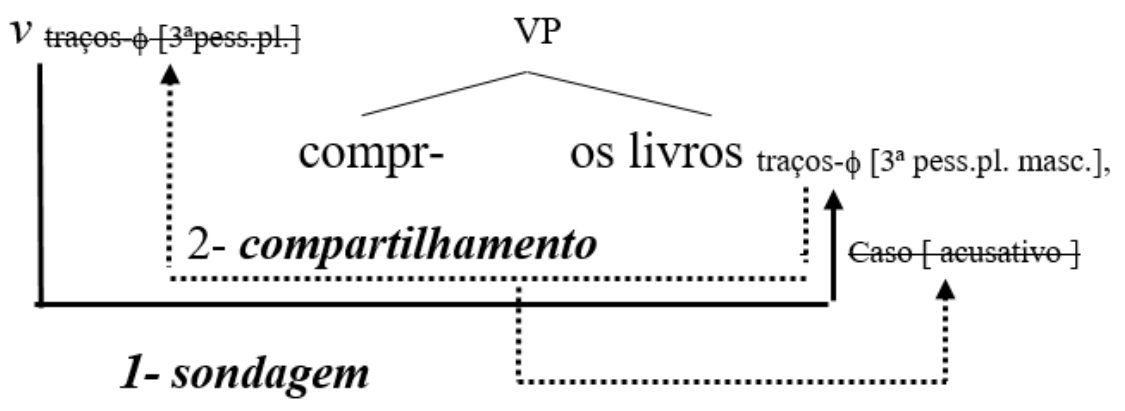

3- compartilhamento

$3^{\circ}$ passo: Concatenação do DP [a maioria dos professores] à estrutura

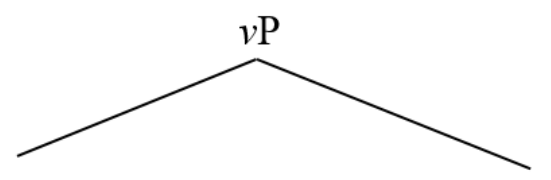

a maioria dos professores

traços- $\phi\left[3^{\mathrm{a}}\right.$ pess. sing. fem.]

Caso [ ]

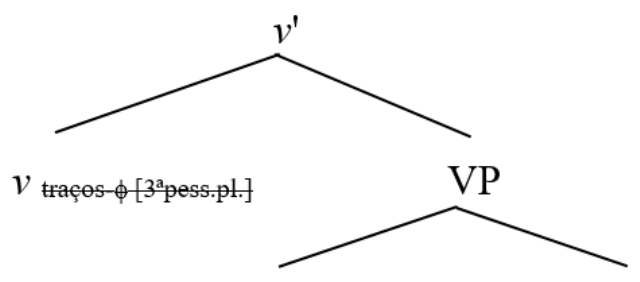

compr-

os livros

traços- $\phi$ [3 $3^{\mathrm{a}}$ pess.pl. masc.],

- Caso [acusativo] 
$4^{\circ}$ passo: Concatenação de $T$ a vP, sondagem e valoração dos traços $\square$ de $T$ e traço de caso do constituinte nominal

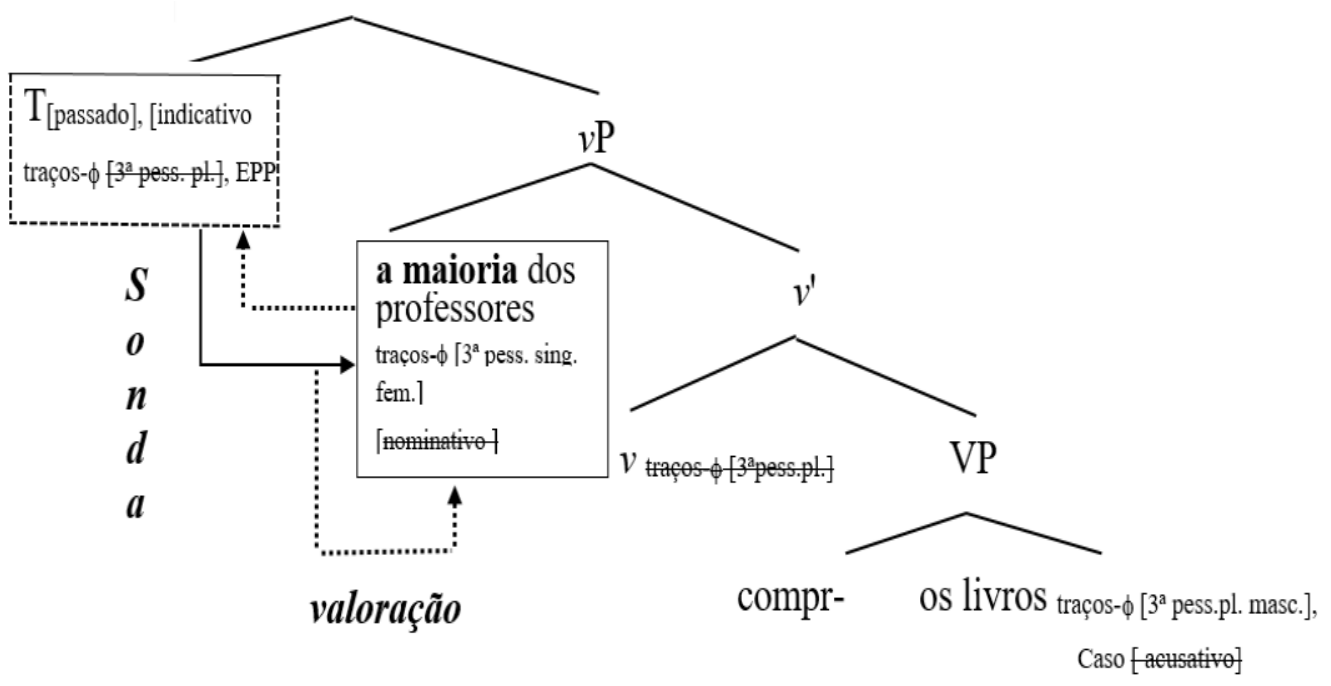

Analisando o procedimento de sondagem e valoração verificado no $4^{\circ}$ passo, voltamos às questões apresentadas anteriormente: (i) de que maneira pode haver valoração dos traços- $\square \square$ de $T$ se parece não haver compatibilidade total de traços na relação sondaalvo, uma vez que o traço de número do DP é marcado com valor singular contrariamente ao traço de número de $\mathrm{T}$ cujo valor é plural; (ii) por que razão a derivação não fracassa/implode? (iii) como resolver esse problema, então?

Para tentar resolver o problema de "aparente" incompatibilidade, parto do princípio de que concordância é uma operação sintática que envolve compartilhamento de traços, conforme propõem Frampton \& Gutmann (2000), Pesetsky \& Torrego (2004) e Carvalho (2008). Seguindo a trilha de Frampton \& Gutmann (2000), um nó sintático transmite seus valores a um dado traço "desprovido" de tal propriedade. Tal ideia é plenamente compatível com a proposta defendida por Béjar (2003), segundo a qual as condições de concordância match (combinação) devem pressupor acarretamento de traço e não identidade, ao contrário de Chomsky (1999).

Nesse sentido, quando a concordância é parcial, o que ocorre na verdade é que, para que a concordância seja possível, deve haver minimamente uma instância de traço comum entre os elementos que entram nessa relação, tal instância é o nó raiz (CARVALHO, 2008, p. 95). 
$5^{\circ}$ passo: Cópia do DP sujeito em Spec de vP para Spec de TP, valoração e apagamento do traço EPP em T

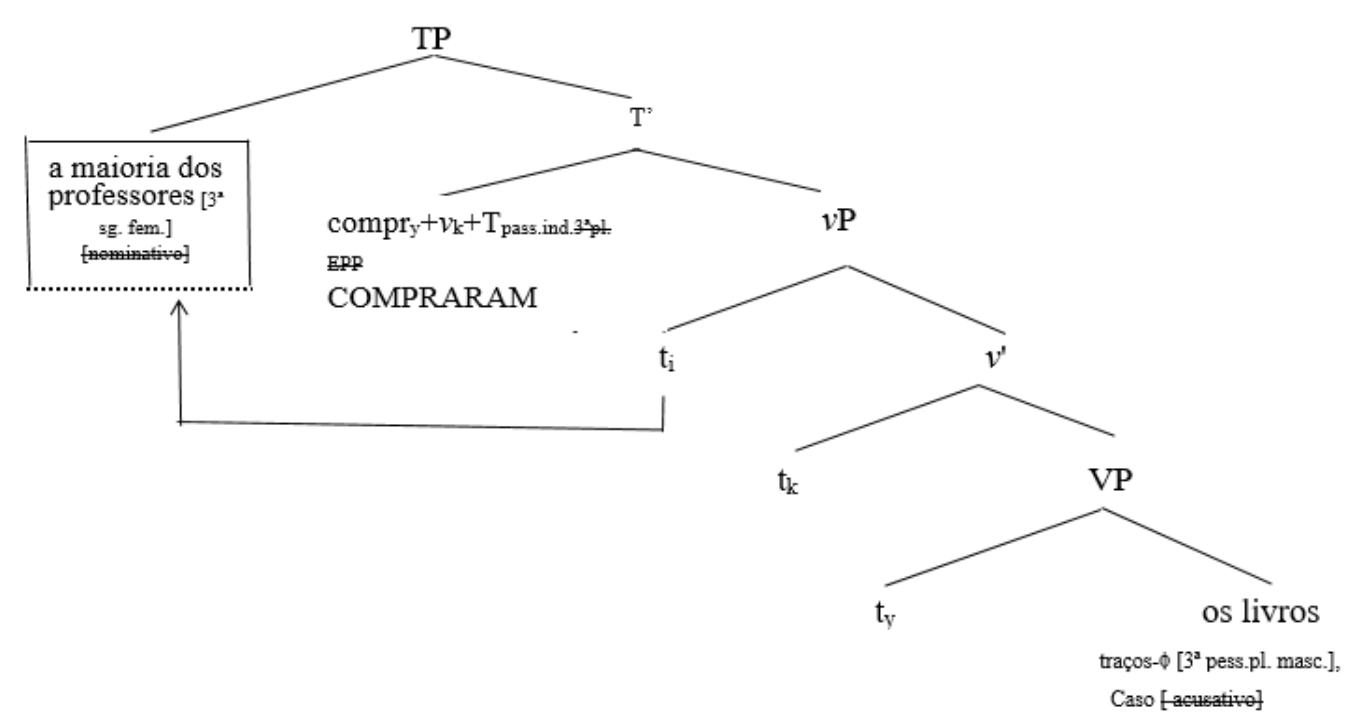

Para tentar responder a tais questões, assumimos as seguintes hipóteses:

1. Concordância é uma operação sintática que envolve compartilhamento de traços, conforme propõem Frampton \& Gutmann (2000), Carvalho (2008), Pesetsky \& Torrego (2004).

2. Quando não há total compartilhamento de traços, a concordância dá-se de forma parcial. Logo, parece não ser necessária a total identidade de traços (BÉJAR, 2003; CARVALHO, 2008).

Essa ideia parece "casar" bem com a ideia de subespecificação de traços. Pode-se pensar na relação de compartilhamento e especificação de traços da seguinte maneira:

(i) um traço $\mathrm{X}$ pode compartilhar apenas determina instancia $\left[\mathrm{X}_{\alpha}\right]$ de traços ou todas

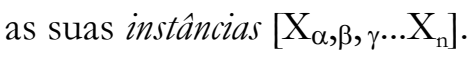

Seguindo a postulação de Carvalho (2008) para a subespecificação dos pronomes com base na noção de "deficiência" postulada em Cardinaletti \& Starke (1999), faço a seguinte predição: 
Um nome é deficiente se carece de, pelo menos, um traço ou uma instância de um dado traço.

O nome contido no núcleo nominal do DP mais encaixado na construção partitiva é, de fato, o nome mais enriquecido do ponto de vista da estrutura traçual, ou seja, traz sobre si traços como referencialidade e pluralidade, o que parece torná-lo, desse modo, mais especificado que o nome partitivo, o qual parece ser deficiente em sua estrutura traçual. Daí seria plausível supor que quanto mais especificado for o nome que entra em relação de concordância com a sonda T, mais concordância morfologicamente visível irá desencadear. Contrariamente, quanto menos especificado, menos concordância morfologicamente visível acarretará, conforme proposto abaixo:

- Nome $[+$ especificado $]=$ maior possibilidade de desencadeamento de concordância morfologicamente visível.

- Nome [-especificado] = menor possibilidade de desencadeamento de concordância morfologicamente visível.

A partir das discussões apresentadas nesta seção, pode-se supor que, mesmo quando totalmente especificado, um traço possa não compartilhar todas as suas instâncias com um outro traço. O contrário também pode ser verdadeiro: mesmo subespecificado, um traço pode compartilhar todas as suas instâncias, ou seja, tudo o que possui, mesmo que esse "tudo" corresponda a uma instância zero $\left[\mathrm{X}_{0}\right]$.

\section{Considerações finais}

Recapitulando o que foi discutido nas seções anteriores, este artigo pretendeu discorrer acerca de dois estudos cuja temática refere-se ao tratamento da concordância de número entre o sujeito e o verbo em construções partitivas e DPs complexos, tentando, de alguma forma, verificar de que maneira eles podem apontar questões elucidativas para o estudo da concordância nas construções mencionadas, tanto na gramática do PB quanto na gramática do PE. Consequentemente, algumas questões foram suscitadas, com o intuito de analisar em que medida os resultados encontrados para os erros de atração, no caso dos DPs complexos, podem ser estendidos, ou não, para uma análise da concordância sujeito-verbo nas construções partitivas, e que implicação poderia acarretar uma tal "associação". A 
respeito da proposta de Rodrigues (2006) acerca da natureza dos itens maioria e parte se faz necessário averiguar se de fato a concordância estaria atrelada às propriedades de tais itens, ou se seria o caso de considerar conjuntamente outras propriedades tais como a natureza dos nomes contidos nos núcleos nominais dos DPs complementos dos nomes partitivos, o tipo de verbo, o tipo de frase, dentre outras condições.

Além disso, é plausível levantar a hipótese de que a variação da concordância nos contextos apresentados seria legitimada pelo mecanismo de Agree, levando em conta as condições sobre match e value, conforme reformuladas por Béjar (2003). Complementando essa ideia, assumimos que a concordância deva ser vista como compartilhamento de traços, seguindo a proposta elaborada por Frampton \& Gutmann (2000).

\section{Referências}

AUGUSTO, M. R. A. As relações com as interfaces no quadro Minimalista Gerativista: uma promissora aproximação com a Psicolinguística. In: MIRANDA, N. S.; NAME, M. C. Linguística e cognição. Juiz de Fora: Ed. UFJF, 2005, p. 245-268.

AVELAR, J. O. Constituintes preposicionados, derivação por fase e critérios de interpretação temática. Trabalho apresentado no GEL - 2005, Universidade Federal de São Carlos, 2005a.

Sobre PPs adnominais no português brasileiro. Trabalho apresentado no X Seminário de Teses em Andamento. Unicamp, 2005b.

Adjuntos adnominais preposicionados no português brasileiro. Tese (Doutorado em Linguística). Campinas: Universidade Estadual de Campinas, 2006.

BÉJAR, S. Phi-Syntax: a theory of agreement. PhD Thesis. Toronto: University of Toronto, 2003.

CARDINALETTI, A.; STARKE, M. The typology of structural deficiency: a case study of the three classes of pronouns. In: VAN RIEMSDIJK, Henk (Org.). Clitics in the languages of Europe. Berlim: Mouton de Gruyter, 1999, p. 145-233.

CARVALHO, D. A estrutura interna dos pronomes pessoais em português brasileiro. Tese (Doutorado em Linguística). Maceió: Universidade Federal de Alagoas, 2008.

CERQUEIRA, M. S. Operação Agree e construções partitivas em português brasileiro e português europeu. Tese (Doutorado em Linguística). Maceió: Universidade Federal de Alagoas, 2009. 
CHOMSKY, N. The Minimalist Program. Cambridge: MIT Press, 1995.

O Programa Minimalista. Trad. Eduardo Paiva Raposo. Lisboa: Editorial Caminho, 1999.

CORREAA, L. M. S. Uma hipótese para a relação entre processador linguístico e gramática numa perspectiva minimalista. Anais do IV Congresso Internacional da ABRALIN, 2005, p. 353-364.

Conciliando processamento linguístico e teoria de língua no estudo da aquisição da linguagem. In: (Org.). Aquisição da linguagem e problemas do desenvolvimento linguístico. Rio de Janeiro: Editora da PUC-RIO/Edições Loyola, 2006.

CORVER, N.; ZWARTS, J. Prepositional numerals. Trabalho apresentado no Workshop on numerals in the World's language, Leipzing, Alemanha, 2004.

FRAMPTON, J.; GUTMANN, S. Agreement is feature sharing. Manuscrito não publicado, Northeastern University, 2000.

FRANCK, J.; VIGLIOCCO, G.; NICOL, J. Subject-verb agreement in French and English: the role of syntactic hierarchy. Language and Cognitive Processes, v. 17, no 4, 2002, p. 371-404.

MATTHEWS, A.; CHODOROW, M. S. Pronoun resolution in two-clause sentences: effect of ambiguity, antecedent location and depth of embedding. Journal of Memory and Language, v. 27, 1988, p. 245-260.

PESETSKY, D.; TORREGO, E. The syntax of valuation and the interpretability of features. Manuscrito não publicado. Massachusetts: MIT, 2004.

RODRIGUES, E. S. O processamento da concordância de número entre sujeito e verbo na produção de sentenças. Tese (Doutorado em Letras). Rio de Janeiro: Pontifícia Universidade Católica do Rio de Janeiro, 2006.

SCHERRE, M. M. P.; NARO, A. J. Restrições sintáticas e semânticas no controle da concordância verbal em português. Fórum Linguístico, v. 1, 1998, p. 45-71. 


\section{Abstract}

This article aims to show the results of investigation about establishment of subject-verb agreement in partitive constructions in Brazilian and European Portuguese. For this purpose, it is organized in three sections. In the first one, we present a brief discussion about a study on processing of number agreement in sentences with partitive constructions in Brazilian Portuguese (RODRIGUES, 2006). In the second one, we describe and analyse a task judgment's results in which we investigate the establishment of agreement in Brazilian and European Portuguese in these constructions (CERQUEIRA, 2009) and we summarize the discussion about them. In the third section, we conclude that subject-verb agreement in partitive constructions can be explained considering Operation Agree interpreted as feature sharing, as proposed by Frampton \& Gutmann (2000).

Keywords: Subject-verb agreement. Partitive constructions. Brazilian Portuguese. European Portuguese 